\title{
Listening to Caregivers' Voices: The Informal Family Caregiver Burden of Caring for Chronically Ill Bedridden Elderly Patients
}

\author{
Jinpitcha Mamom ${ }^{1,2, *(1)}$ and Hanvedes Daovisan ${ }^{3}$ (1) \\ 1 Department of Adult Nursing and the Aged, Faculty of Nursing, Thammasat University, \\ Khlong Luang, Pathum Thani 12121, Thailand \\ 2 Excellence Center in Creative Engineering Design and Development, Faculty of Engineering, \\ Thammasat University, Khlong Luang, Pathum Thani 12121, Thailand \\ 3 Human Security and Equity Research Unit, Chulalongkorn University Social Research Institute, \\ Chulalongkorn University, Bangkok 10330, Thailand; hanvedes.d@chula.ac.th \\ * Correspondence: jinpitcha@nurse.tu.ac.th
}

Citation: Mamom, J.; Daovisan, $\mathrm{H}$. Listening to Caregivers' Voices: The Informal Family Caregiver Burden of Caring for Chronically Ill Bedridden Elderly Patients. Int. J. Environ. Res. Public Health 2022, 19, 567. https://doi.org/10.3390/ ijerph19010567

Academic Editor: Steven A. Cohen

Received: 16 November 2021

Accepted: 30 December 2021

Published: 5 January 2022

Publisher's Note: MDPI stays neutral with regard to jurisdictional claims in published maps and institutional affiliations.

Copyright: (C) 2022 by the authors. Licensee MDPI, Basel, Switzerland. This article is an open access article distributed under the terms and conditions of the Creative Commons Attribution (CC BY) license (https:// creativecommons.org/licenses/by/ $4.0 /)$.

\begin{abstract}
The informal family caregiver burden (IFCB) for chronically ill bedridden elderly patients (CIBEPs) is a major issue worldwide. It is a significant challenge due to the ongoing increased palliative care in the family setting; therefore, we explored the IFCB of caring for CIBEPs in Thailand This article utilized a qualitative method, the total interpretive structural modeling (TISM) approach, with purposive sampling of thirty respondents between September and December 2020. The data were analyzed using cross-impact matrix multiplication applied to classification (MICMAC) to determine the relationship between the driving and dependence power of the enabling factors. The IFCB of the palliative care of CIBEPs was associated with primary care, nursing, extrinsic monitoring and complication prevention. The results showed that the IFCB involves taking responsibility, daily workload, follow-up caring, caring tasks, caregiving strain, financial distress, patient support, external support and caregiving strategy; thus, assistance with taking responsibility, extrinsic monitoring and follow-up care daily tasks may reduce the caregiver burden.
\end{abstract}

Keywords: informal caregiver burden; chronic illness; palliative care; bedridden elderly patient; Thailand

\section{Introduction}

In Thailand, there is a continually increasing need for palliative care post-hospitalization of elderly patients, particularly in family caregiver settings [1]. The primary care of CIBEPs is often provided by caregivers [2]. Kulkantrakorn and Suksasunee [3] reported that ALS is the second major cause of CIBEPs in Thailand as well as globally. Some studies classified that CIBEPs are related to communicable diseases and non-communicable diseases (NCDs) in the palliative care setting [4].

Caring for CIBEPs is a global issue [5], but there is a lack of data linking theory and practice [6]. Previous studies have identified that the palliative care of CIBEPs is holistic rather than clinical [7], while focusing on the different NCDs [8]. Some scholars criticized that not all IFCB in palliative care can reduce the care burden $[9,10]$. Previous studies suggest that the overall trajectory of caring, in particular, caregiver's voices of subsequent the care burden [11,12].

Caregivers live with poor physical health, psychological stress and economic problems, which increase their burden [13,14]. One-third of IFCB is related to psychosocial distress [15] and poor mental health [16], with an acute health-related workload [17]. Some studies have found that the IFCB is negatively impacted by both palliative care and caregivers, such as caring tasks, fracture, monitoring, primary treatment and responsibility [6].

Despite the growing interest in the IFCB of caring for CIBEPs, few studies have explored the care burden setting. Therefore, this study investigated the palliative care tasks (primary caring treatment, performing nursing, extrinsic monitoring and complication 
prevention) associated with the IFCB for caring of CIBEPs (taking responsibility, daily workload, financial distress and caregiving strategy).

\section{Context and Theoretical Background}

\subsection{Context of Bedridden Elderly Patients in Thailand}

Thailand is a large country with an increasingly aging population [2,4]. According to the United Nations [18], Thailand is a completely aging society (aged $\geq 60$ years), increasing from $15.6 \%$ in 2015 to $30.2 \%$ in 2035 . As a result of this rapid change, caregivers in Thailand are facing challenges in caring for chronically ill patients. Furthermore, Kulkantrakorn and Suksasunee [3] point out that elderly Thai patients are at high risk of NCDs and ALS. Indeed, some $80-90 \%$ of elderly individuals have one chronic illness, and $50-77 \%$ have experienced a chronic illness more than twice [19]. Elderly Thais with chronic illness may be grouped as social, home, bedridden or dead [20]. In 2015, the Thai Ministry of Public Health reported that five million elderly patients, accounting for $21 \%$, were living with chronic disease at home.

The central region of Thailand has a high concentration of CIBEPs, with conditions such as hypertension, diabetes, stroke and coronary artery diseases [19,21-23]. Suriyanrattakorn and Chang [4] defined that bedridden elderly patients have both formal (paid caregivers) and informal (unpaid caregivers) care at home. Hence, in this study we explored the care burden of unpaid caregivers providing palliative care of CIBEPs in the central region of Thailand.

\subsection{Palliative Care}

As palliative care of CIBEPs [24-26] is classified as prevention or treatment, we focused on life-preventing diseases (routine screening, assessment, support of care and advanced patient care) and life-threatening diseases (primary caring, performing nursing and extrinsic monitoring). Palliative care entails taking responsibility for preventing rather than treating as caregivers, which leads to a high care burden [27].

Previous studies indicated that palliative care provides a balance between the care burden and maintaining daily life $[28,29]$. The dominant ideal in Western palliative care emphasizes the patient's ability to prevent and treat as caregivers [30], whereas in Asia, palliative care is performed by family caregivers [31]. These views are also supported in the recent studies of palliative care in South Asia [32], which focused on family-centered caregivers.

Palliative care is holistic [33], focusing on the quality of life of the patients, their families and caregivers. For many NCDs, palliative care has focused on prevention, treatment and life-sustaining care [34-36]. However, some studies concerning palliative care have specified patient types, as well as caregiver issues [37-39]. Palliative care of CIBEP was secondary caring burden at home [24,40]. However, caregivers in palliative care unsolved problems or unmet needs reducing the care burden [41-43].

\subsection{Informal Family Caregiver Burden}

Regarding caregivers and their patients as the "unit of care" is the principle of the IFCB setting $[44,45]$. Previous literature defined the IFCB as comprising various mental, social, physical and economic factors associated with the care burden [46]. Some studies have classified the relationship between caregiving and caregivers as perceived as negative, positive or a combination of both [12]. Caregivers provide varying care provisions throughout the day and have negative feelings toward acute health-related quality of life [42].

Numerous studies have indicated that the IFCB is associated with the caring strategy, follow-up tasks and daily workload [41,47]. Most caregivers are confronted with financial, emotional, physical and social caregiving $[48,49]$. Caregivers have the greatest care-induced burden, which is associated with health outcomes, support and responsibility [50,51]. Since caregivers tend to lack access to professional care and have limited care-related training, this may increase their care burden [43]. Nonetheless, the care burden can be reduced if the caregivers receive assistance with skin cleaning, follow-up care and support [8]. Caregivers 
include non-professional nurses such as family members, friends and paid caregivers who provide care at home [52]. Caregivers may also feel overwhelmed and have limited resources for care provision, and thus are at highest risk of a high level of care burden. Thus, it was hypothesized that the palliative care of CIBEPs is associated with an IFCB.

\section{Methods}

\subsection{Study Design}

This study utilized a qualitative TISM approach [53] to interpret the complex relationship and digraph model [54], as illustrated in Figure 1. The structural mapping of the relationships between the elements involved in informal caregiving provided a visual representation of the model [55,56]. Mathiyazhagan et al. [57] state that principle of the TISM approach is to use respondents' experience and practical knowledge to decompose a complex system and generate a multi-level structural model.

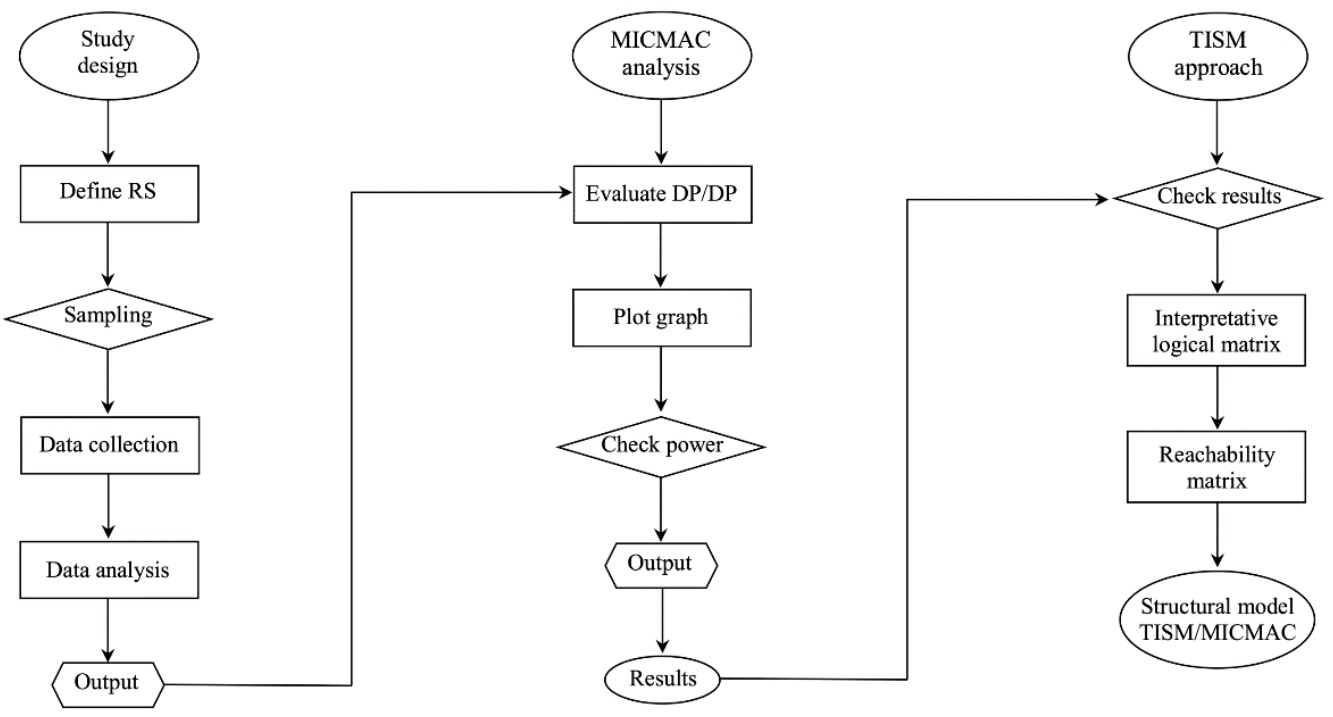

Figure 1. Flowchart of the TISM approach.

\subsection{Respondents and Sampling}

This study was conducted in the Ayutthaya, Angthong and Pratumthani provinces in Central Thailand. The inclusion criteria were caregivers of elderly patients aged 60 years and above, those immobilized and receiving care from informal family caregivers or bedridden patients with NCDs. The respondent characteristics are provided in Table 1.

Table 1. Respondent characteristics.

\begin{tabular}{cccccccccc}
\hline ID & CGG & CGA & MS & ED & Underlying & CD & Relationship & $\begin{array}{c}\text { Income } \\
\text { Adequacy }\end{array}$ & $\begin{array}{c}\text { Medical } \\
\text { Welfare }\end{array}$ \\
\hline 1 & Female & 61 & Married & ES & Yes & 2 months & Spouse & Yes & - \\
\hline 2 & Female & 44 & Single & ES & Yes & 8 months & Son/daughter & No & UC \\
\hline 3 & Male & 49 & Married & ES & Yes & 5 months & Son/daughter & Yes & UC \\
\hline 4 & Male & 53 & Single & ES & Yes & 5 months & Son/daughter & Yes & UC \\
\hline 5 & Female & 34 & Married & ES & Yes & 3 months & Son/daughter & Yes & UC \\
\hline 6 & Female & 37 & Single & Diploma & Yes & 6 months & Son/daughter & No & - \\
\hline 7 & Female & 53 & Married & BA & Yes & 10 months & Spouse & No & - \\
\hline 8 & Female & 47 & Single & BA & Yes & 3 months & Son/daughter & Yes & - \\
\hline 9 & Male & 70 & Married & BA & Yes & 1 months & Spouse & Yes & CSMBS \\
\hline
\end{tabular}


Table 1. Cont.

\begin{tabular}{|c|c|c|c|c|c|c|c|c|c|}
\hline ID & CGG & CGA & MS & ED & Underlying & CD & Relationship & $\begin{array}{c}\text { Income } \\
\text { Adequacy }\end{array}$ & $\begin{array}{l}\text { Medical } \\
\text { Welfare }\end{array}$ \\
\hline 10 & Female & 36 & Married & BA & Yes & 8 months & Son/daughter & Yes & CSMBS \\
\hline 11 & Female & 37 & Single & - & Yes & 5 months & Son/daughter & No & CSMBS \\
\hline 12 & Female & 47 & Married & HS & Yes & 2 months & Son/daughter & Yes & CSMBS \\
\hline 13 & Female & 61 & Married & Diploma & Yes & 6 months & Spouse & No & UC \\
\hline 14 & Male & 59 & Married & HS & Yes & 2 months & Spouse & Yes & - \\
\hline 15 & Male & 59 & Married & ES & Yes & 3 months & Spouse & Yes & CSMBS \\
\hline 16 & Female & 44 & Widow & ES & Yes & 5 months & Brother/sister & Yes & CSMBS \\
\hline 17 & Male & 52 & Widow & ES & Yes & 2 months & Spouse & Yes & - \\
\hline 18 & Female & 49 & Single & - & Yes & 5 months & Spouse & Yes & - \\
\hline 19 & Male & 58 & Single & - & Yes & 8 months & Spouse & No & CSMBS \\
\hline 20 & Female & 58 & Single & - & Yes & 5 months & Spouse & No & - \\
\hline 21 & Female & 59 & Single & ES & Yes & 8 months & Spouse & Yes & CSMBS \\
\hline 22 & Male & 52 & Widow & ES & Yes & 2 months & Brother/sister & No & CSMBS \\
\hline 23 & Female & 44 & Widow & HS & Yes & 6 months & Son/daughter & Yes & - \\
\hline 24 & Female & 39 & Single & Diploma & Yes & 2 months & Son/daughter & No & - \\
\hline 25 & Female & 40 & Married & ES & Yes & 2 months & Son/daughter & Yes & CSMBS \\
\hline 26 & Female & 45 & Married & ES & Yes & 8 months & Son/daughter & Yes & - \\
\hline 27 & Male & 44 & Widow & ES & Yes & 2 months & Son/daughter & Yes & CSMBS \\
\hline 28 & Male & 62 & Widow & - & Yes & 7 months & Spouse & No & $\mathrm{UC}$ \\
\hline 29 & Female & 44 & Single & ES & Yes & 7 months & Son/daughter & Yes & CSMBS \\
\hline 30 & Male & 61 & Widow & - & Yes & 5 months & Spouse & No & CSMBS \\
\hline
\end{tabular}

Note: CGG, caregiver gender; CGA, caregiver age; MS, marital status; ED, education level; CD, caring duration; UC, universal coverage; CSMBS, civil servant medical benefit scheme.

\subsection{In-Depth Interview Questions}

One-on-one in-depth interviews (Table 2) were conducted from September to December 2020 at the respondents' home addresses, with an average interview duration of between 30 and 40 min per respondent. In-depth interviews were conducted in Thai and subsequently translated into English by the first author. The respondents were encouraged to provide a detailed description of palliative care and care burden. Each session was digitally recorded, then transcribed immediately after the interview.

Table 2. Interview questions.

\begin{tabular}{ccc}
\hline Theme & Issue & Interview Questions \\
\hline & $\begin{array}{c}\text { Palliative care background } \\
\text { Palliative care experience }\end{array}$ & $\begin{array}{c}\text { Could you please describe your caregiving history from } \\
\text { your experience with palliative care? }\end{array}$ \\
\cline { 2 - 3 } Palliative care & Palliative care problems & $\begin{array}{c}\text { What are the most important problems associated with } \\
\text { palliative care? }\end{array}$ \\
\cline { 2 - 3 } & $\begin{array}{c}\text { Primary caring } \\
\text { Perform nursing } \\
\text { Extrinsic monitoring } \\
\text { Complication prevention }\end{array}$ & $\begin{array}{c}\text { What could help you in primary caring, perform nursing, } \\
\text { extrinsic monitoring, and complication prevention for } \\
\text { treatment in palliative care? }\end{array}$ \\
\hline
\end{tabular}


Table 2. Cont.

\begin{tabular}{|c|c|c|}
\hline Theme & Issue & Interview Questions \\
\hline \multirow{4}{*}{$\begin{array}{l}\text { Informal caregiver } \\
\text { burden }\end{array}$} & $\begin{array}{l}\text { Caregiver role } \\
\text { Caregivers daily task } \\
\text { Taking responsibility }\end{array}$ & $\begin{array}{l}\text { What are the most important aspects important aspects of } \\
\text { caregivers' roles, daily activities, and responsibilities? }\end{array}$ \\
\hline & $\begin{array}{l}\text { Daily workload } \\
\text { Follow-up caring } \\
\text { Caring task }\end{array}$ & $\begin{array}{l}\text { What is your daily workload, follow-up caring, and caring } \\
\text { tasks associated with caregiver burden? }\end{array}$ \\
\hline & $\begin{array}{l}\text { Caregiving strain } \\
\text { Financial distress } \\
\text { Support of patient } \\
\text { External support }\end{array}$ & $\begin{array}{l}\text { How does your caregiving strain, financial distress, support } \\
\text { of the patient, and external support make you feel burdened } \\
\text { for caring? }\end{array}$ \\
\hline & Caregiving strategy & $\begin{array}{c}\text { Can you share with us your caregiving strategy for caring } \\
\text { for an elderly patient in your family? }\end{array}$ \\
\hline
\end{tabular}

\subsection{Data Analysis}

Data were analyzed using MICMAC, determining the driving (influential) power and dependence (influenced) power of each element [58]. The key factors (autonomous, linkage, dependent and independent) were defined as follows:

- Autonomous factors are both weak driving and dependence powers, which disconnect with others but are strongly linked with a few strong factors.

- Linkage factors are both strong driving and dependence powers, that is, factors act as linking (bridge) connectors with autonomous/dependent factors, which connect with independent factors.

- Dependent factors are less influential powers but have strong dependence power that influences the linkage/independent factors.

- Independent factors are strong influencing autonomous/dependent factors, which also are a strong driving power but have less dependence power.

\subsection{Data Validity}

The TIMS approach to the IFCB of caring for CIBEPs needs further validation, as it was developed with respondent views [59]. Thus, the accuracy of the elements used to build the model and the relationships of the TIMS model were cross-checked, verifying that the elements were relevant to the study context. Sushil [60] suggested checking the reachability matrix between the direct links and transitive links to validate the final transitive model of the TISM approach.

\section{Results}

The MICMAC was analyzed using responses of the thirty caregivers of CIBEPs, generating 150 codes categorized into two themes (palliative care and IFCB) as shown in Tables 3 and 4.

\subsection{Interpretive Logic Matrix}

The respondents' view of their experiences of caring for CIBEPs identified thirteen enabling tasks, as listed in Table 3. The logic matrix uses the symbols $I$ and $j$ to denote the direction nodes of ' $V$ ' which denotes the relationship with ' $i$ ', which leads to ' $j$ ' but ' $j$ ' does not lead to ' $i$ '. The model denoted ' $A$ ' enables the relationship with ' $j$ ' helping to achieve ' $i$ ', but enabling ' $i$ ' does not help to enable ' $j$ '. As elements of ' $X$ ' denote the relationship between both tasks, ' $i$ ' and ' $j$ ' help each other; similarly, ' $\mathrm{O}$ ' represents a relationship and association with the other. The following four symbols denote the associations between elements $i$ and $j$ as shown in Table 5:

- V: element $i$ will help to achieve factor $j$;

- A: element $j$ will help to achieve factor $i$;

- $\quad X$ : element $i$ and $j$ will help to achieve each other;

- $\quad$ O: element $i$ and $j$ are unrelated. 
Table 3. The themes and what they enabled $(n=30)$.

\begin{tabular}{|c|c|c|c|c|c|}
\hline \multirow{2}{*}{ Theme } & \multirow{2}{*}{ Enables } & \multirow{2}{*}{ Acronym } & \multicolumn{2}{|c|}{ Respondents Confirmed } & \multirow{2}{*}{ Frequency $(\%)$} \\
\hline & & & Time 1 & Time 2 & \\
\hline \multirow{4}{*}{ Palliative care } & Primary caring treatment & PCT (1) & $\sqrt{ }$ & $\sqrt{ }$ & $28(93.33)$ \\
\hline & Performing nursing & PNU (2) & $\sqrt{ }$ & $\sqrt{ }$ & $27(90)$ \\
\hline & Extrinsic monitoring & EXM (3) & $\sqrt{ }$ & $\sqrt{ }$ & $30(100)$ \\
\hline & Complication prevention & COP (4) & $\sqrt{ }$ & $\sqrt{ }$ & $30(100)$ \\
\hline \multirow{9}{*}{$\begin{array}{l}\text { Informal caregiver } \\
\text { burden }\end{array}$} & Taking responsibility & TRS (5) & $\sqrt{ }$ & $\sqrt{ }$ & $30(100)$ \\
\hline & Daily workload & DWL (6) & $\sqrt{ }$ & $\sqrt{ }$ & $30(100)$ \\
\hline & Follow-up caring & FCA (7) & $\sqrt{ }$ & $\sqrt{ }$ & $26(86.66)$ \\
\hline & Caring task & CAT (8) & $\sqrt{ }$ & $\sqrt{ }$ & $30(100)$ \\
\hline & Caregiving strain & CVS (9) & $\sqrt{ }$ & $\sqrt{ }$ & $25(83.33)$ \\
\hline & Financial distress & FID (10) & $\sqrt{ }$ & $\sqrt{ }$ & $24(80)$ \\
\hline & Support of patient & SUP (11) & $\sqrt{ }$ & $\sqrt{ }$ & $30(100)$ \\
\hline & External support & EXS (12) & $\sqrt{ }$ & $\sqrt{ }$ & $21(70)$ \\
\hline & Caregiving strategy & CGS (13) & $\sqrt{ }$ & $\sqrt{ }$ & $29(96.66)$ \\
\hline
\end{tabular}

Table 4. Respondents' confirmed coding.

\begin{tabular}{|c|c|c|c|c|c|c|c|c|c|c|c|c|c|c|c|}
\hline & (1) & $(2)$ & (3) & $(4)$ & (5) & (6) & (7) & $(8)$ & (9) & (10) & (11) & (12) & (13) & (14) & (15) \\
\hline 1 & * & * & * & * & * & * & - & * & * & * & * & * & - & $*$ & * \\
\hline 2 & * & * & * & $*$ & $*$ & * & * & * & * & * & * & * & * & $*$ & - \\
\hline 3 & * & * & * & $*$ & * & * & $*$ & * & * & * & * & * & * & $*$ & $*$ \\
\hline 4 & $*$ & $*$ & * & * & * & * & * & * & $*$ & * & $*$ & * & * & $*$ & $*$ \\
\hline 5 & * & $*$ & * & * & $*$ & * & * & * & * & * & * & * & * & $*$ & $*$ \\
\hline 6 & * & * & * & * & * & * & * & $*$ & * & * & * & * & * & * & $*$ \\
\hline 7 & * & * & * & - & * & * & * & * & * & - & * & * & * & * & $*$ \\
\hline 8 & $*$ & $*$ & $*$ & $*$ & $*$ & $*$ & $*$ & $*$ & $*$ & $*$ & $*$ & $*$ & $*$ & $*$ & $*$ \\
\hline 9 & - & * & * & * & * & * & * & * & * & * & * & * & * & * & - \\
\hline 10 & $*$ & * & - & $*$ & * & * & $*$ & - & * & * & * & - & $*$ & * & $*$ \\
\hline 11 & * & * & * & * & * & * & * & * & * & * & * & * & * & * & * \\
\hline 12 & * & * & * & - & * & * & - & - & $*$ & * & - & * & * & $*$ & - \\
\hline \multirow[t]{2}{*}{13} & * & * & * & * & * & * & * & * & * & * & * & * & * & * & $*$ \\
\hline & (16) & (17) & (18) & (19) & (20) & (21) & (22) & (23) & (24) & (25) & (26) & (27) & (28) & (29) & (30) \\
\hline 1 & * & * & * & * & * & * & * & * & $*$ & * & * & * & * & * & $*$ \\
\hline 2 & * & $*$ & * & - & $*$ & * & $*$ & * & $*$ & * & $*$ & - & $*$ & $*$ & $*$ \\
\hline 3 & * & $*$ & $*$ & $*$ & $*$ & * & $*$ & $*$ & $*$ & $*$ & * & $*$ & $*$ & * & $*$ \\
\hline 4 & * & * & * & * & $*$ & * & $*$ & $*$ & $*$ & $*$ & * & $*$ & $*$ & * & $*$ \\
\hline 5 & * & * & * & * & * & * & * & * & * & * & * & * & * & $*$ & $*$ \\
\hline 6 & * & $*$ & $*$ & $*$ & $*$ & * & $*$ & $*$ & * & $*$ & $*$ & * & $*$ & $*$ & $*$ \\
\hline 7 & $*$ & $*$ & $*$ & $*$ & $*$ & $*$ & $*$ & - & $*$ & $*$ & $*$ & * & $*$ & $*$ & - \\
\hline 8 & * & * & $*$ & $*$ & $*$ & * & $*$ & * & $*$ & * & * & * & $*$ & * & $*$ \\
\hline 9 & - & $*$ & $*$ & $*$ & * & - & $*$ & $*$ & $*$ & * & $*$ & * & - & * & $*$ \\
\hline 10 & * & * & - & $*$ & * & * & $*_{-}$ & $*$ & $*$ & * & - & * & * & * & $*$ \\
\hline 11 & * & * & $*$ & $*$ & * & * & $*$ & $*$ & $*$ & * & * & $*$ & * & * & $*$ \\
\hline 12 & $*$ & - & * & - & - & * & $*$ & - & $*$ & $*$ & $*$ & * & $*$ & $*$ & $*$ \\
\hline 13 & $*$ & $*$ & $*$ & $*$ & $*$ & - & $*$ & $*$ & $*$ & * & $*$ & * & $*$ & $*$ & $*$ \\
\hline
\end{tabular}


Table 5. Structural self-interaction matrix.

\begin{tabular}{|c|c|c|c|c|c|c|c|c|c|c|c|c|c|}
\hline IFCB Descriptions & (1) & $(2)$ & (3) & (4) & (5) & (6) & (7) & (8) & (9) & (10) & (11) & (12) & (13) \\
\hline 1 & $X$ & $\mathrm{~V}$ & $X$ & $X$ & $X$ & $X$ & $X$ & $X$ & $\mathrm{~V}$ & $\mathrm{~V}$ & $\mathrm{~V}$ & $\mathrm{~V}$ & $\mathrm{~V}$ \\
\hline 2 & $X$ & $\mathrm{~V}$ & $\mathrm{~V}$ & $\mathrm{~V}$ & $\mathrm{O}$ & $X$ & $\mathrm{O}$ & $\mathrm{O}$ & $\mathrm{V}$ & $\mathrm{O}$ & $\mathrm{V}$ & $\mathrm{O}$ & $\mathrm{V}$ \\
\hline 3 & $X$ & $x$ & $X$ & $X$ & $x$ & $X$ & $X$ & $\mathrm{~V}$ & $\mathrm{~V}$ & $\mathrm{~V}$ & $\mathrm{~V}$ & $\mathrm{~V}$ & $\mathrm{~V}$ \\
\hline 4 & $X$ & $x$ & $X$ & $X$ & $X$ & $X$ & $X$ & $X$ & $X$ & $\mathrm{~V}$ & $\mathrm{~V}$ & $\mathrm{O}$ & $\mathrm{V}$ \\
\hline 5 & $X$ & $x$ & $X$ & $X$ & $X$ & $X$ & $X$ & $X$ & $X$ & $x$ & $\mathrm{O}$ & $\mathrm{V}$ & $\mathrm{V}$ \\
\hline 6 & $X$ & $x$ & $X$ & $\mathrm{~V}$ & $X$ & $X$ & $\mathrm{~V}$ & $X$ & $\mathrm{~V}$ & $\mathrm{O}$ & $\mathrm{O}$ & $\mathrm{O}$ & $x$ \\
\hline 7 & $\mathrm{~V}$ & $x$ & $X$ & $\mathrm{~V}$ & $X$ & $\mathrm{~V}$ & $\mathrm{~V}$ & $\mathrm{~V}$ & $X$ & $\mathrm{O}$ & $X$ & $\mathrm{O}$ & $X$ \\
\hline 8 & $X$ & $X$ & $X$ & $\mathrm{O}$ & $X$ & $X$ & $\mathrm{~V}$ & $X$ & $\mathrm{~V}$ & $\mathrm{O}$ & $\mathrm{V}$ & $\mathrm{O}$ & $\mathrm{O}$ \\
\hline 9 & $X$ & $X$ & $X$ & $\mathrm{O}$ & $\mathrm{O}$ & $\mathrm{O}$ & $\mathrm{O}$ & $X$ & $X$ & V & $x$ & $\mathrm{O}$ & $\mathrm{V}$ \\
\hline 10 & $\mathrm{O}$ & $\mathrm{O}$ & $\mathrm{O}$ & $\mathrm{O}$ & $x$ & $\mathrm{O}$ & $\mathrm{O}$ & $\mathrm{O}$ & $X$ & $\mathrm{~V}$ & $x$ & $\mathrm{O}$ & $\mathrm{O}$ \\
\hline 11 & $\mathrm{O}$ & $\mathrm{O}$ & $\mathrm{O}$ & $\mathrm{O}$ & $\mathrm{O}$ & $\mathrm{O}$ & $\mathrm{V}$ & $X$ & $X$ & $\mathrm{~V}$ & $x$ & $x$ & $\mathrm{O}$ \\
\hline 12 & $X$ & $\mathrm{~V}$ & $X$ & $X$ & $\mathrm{O}$ & $\mathrm{O}$ & $\mathrm{V}$ & $\mathrm{O}$ & $\mathrm{O}$ & $\mathrm{O}$ & $\mathrm{O}$ & $X$ & $x$ \\
\hline 13 & $X$ & $X$ & $X$ & $\mathrm{~V}$ & $\mathrm{O}$ & $\mathrm{O}$ & $X$ & $\mathrm{O}$ & $\mathrm{O}$ & $\mathrm{O}$ & $\mathrm{O}$ & $X$ & $x$ \\
\hline
\end{tabular}

\subsection{Reachability Matrix}

To develop a structural self-interaction matrix (SSIM), the initial reachability matrix substituted V, A, X and $\mathrm{O}$ as 1 and 0 as suggested by Singh and Kant [61] and shown in Table 6.

Table 6. Initial reachability matrix.

\begin{tabular}{|c|c|c|c|c|c|c|c|c|c|c|c|c|c|c|c|}
\hline \multirow{2}{*}{ Enables } & \multicolumn{13}{|c|}{ IFCB of Caring for CIBEPs } & \multirow{2}{*}{ Driving Power } & \multirow{2}{*}{ Rank } \\
\hline & (1) & (2) & (3) & (4) & (5) & (6) & (7) & (8) & (9) & (10) & (11) & (12) & (13) & & \\
\hline 1 & 1 & 1 & 1 & 1 & 1 & 1 & 1 & 1 & 1 & 1 & 1 & 1 & 1 & 13 & 1 \\
\hline 2 & 1 & 1 & 1 & 1 & 0 & 1 & 0 & 0 & 1 & 0 & 1 & 0 & 1 & 8 & 5 \\
\hline 3 & 1 & 1 & 1 & 1 & 1 & 1 & 1 & 1 & 1 & 1 & 1 & 1 & 1 & 13 & 1 \\
\hline 4 & 1 & 1 & 1 & 1 & 1 & 1 & 1 & 1 & 1 & 1 & 1 & 0 & 1 & 12 & 2 \\
\hline 5 & 1 & 1 & 1 & 1 & 1 & 1 & 1 & 1 & 1 & 1 & 0 & 1 & 1 & 12 & 2 \\
\hline 6 & 1 & 1 & 1 & 1 & 1 & 1 & 1 & 1 & 1 & 0 & 0 & 0 & 1 & 10 & 4 \\
\hline 7 & 1 & 1 & 1 & 1 & 1 & 1 & 1 & 1 & 1 & 0 & 1 & 0 & 1 & 11 & 3 \\
\hline 8 & 1 & 1 & 1 & 0 & 1 & 1 & 1 & 1 & 1 & 0 & 1 & 0 & 0 & 8 & 5 \\
\hline 9 & 1 & 1 & 1 & 0 & 0 & 0 & 0 & 1 & 1 & 1 & 1 & 0 & 1 & 8 & 5 \\
\hline 10 & 0 & 0 & 0 & 0 & 1 & 0 & 0 & 0 & 1 & 1 & 1 & 0 & 0 & 4 & 7 \\
\hline 11 & 0 & 0 & 0 & 0 & 0 & 0 & 1 & 1 & 1 & 1 & 1 & 1 & 0 & 6 & 6 \\
\hline 12 & 0 & 0 & 1 & 0 & 1 & 0 & 0 & 0 & 0 & 0 & 0 & 1 & 1 & 4 & 7 \\
\hline 13 & 1 & 1 & 1 & 1 & 0 & 0 & 1 & 0 & 0 & 0 & 0 & 1 & 1 & 6 & 6 \\
\hline Dependence power & 10 & 10 & 10 & 8 & 7 & 8 & 9 & 9 & 11 & 7 & 8 & 6 & 10 & & \\
\hline
\end{tabular}

If the $(i, j)$ entry in the SSIM is $\mathrm{V}$, the $(i, j)$ entry with the reachability matrix of 1 and the $(i, j)$ entry become 0 ;

If the $(i, j)$ entry in the SSIM is A, the $(i, j)$ entry with the reachability matrix of 0 and the $(j, i)$ entry become 1 ;

If the $(i, j)$ entry in the SSIM is $X$, the $(i, j)$ entry with the reachability matrix of 1 and the $(j, i)$ entry also become 1 ;

If the $(i, j)$ entry in the SSIM is $\mathrm{O}$, the $(i, j)$ entry with the reachability matrix of 0 and the $(j, i)$ entry become 0 .

The reachability matrix indicated the PCT and EXM values of driving power 13 and dependence power 10. The PNU values were driving power 8 and dependence power 10, and for COP the driving power 12 and dependence power was 8 . The TRS had a value of driving power 12 and a dependence power of 8 , while DWL had driving power 10 and dependence power 8 .

The FCA driving power 11 was associated with a dependence power of 9 , and CAT had a driving power of 8 and dependence power of approximately 9 . The CVS driving 
power was 8 and dependence power was 11, while FID had a driving power equivalent to 4 and a dependence power of 7 . The SUP, EXS and CGS had driving powers of 6,4 and 6 , and dependence powers of 8,6 and 10, respectively.

\subsection{Structural Model}

The structural model was generated based on the reachability matrix, which discards the transitivity of TISM (Figure 2). The reachability set consists of one element and another which may help to achieve the antecedent set (driving and dependence power), antecedent factors (dependence power) and intersection set (reachability and antecedent set) (Table 7). The ranking level of the remaining IFCB of caring for CIBEPs was determined according to the numbers of all critical factors, which are presented in Table 8. The identified level was used to build the structural model, as shown in Figure 3.

Table 7. Level partition of each iteration.

\begin{tabular}{ccccc}
\hline IFCB & Reachability Set & Antecedent Set & Intersection Set & Level \\
\hline 1 & $1,3,5,7,9,13$ & $1,2,3,4,5,6,7,8,9,10,11,12,13$ & $1,3,5,7,9,13$ \\
2 & $1,2,3,4,6,9,11,13$ & $1,2,3,4,6,9,11,13$ & $1,2,3,4,6,9,11,13$ \\
3 & $1,2,3,4,5,6,7,8,9,10,11,12,13$ & $1,2,3,4,5,6,7,8,9,10,11,12,13$ & $1,2,3,4,5,6,7,8,9,10,11,12,13$ \\
4 & $1,2,3,4,5,6,7,8,9,10,11,13$ & $1,2,3,4,5,6,7,8,9,10,11,13$ & $1,2,3,4,5,6,7,8,9,10,11,13$ \\
5 & $1,2,3,4,5,6,7,8,9,10,12,13$ & $1,2,3,4,5,6,7,8,9,10,12,13$ & $1,2,3,4,5,6,7,8,9,10,12,13$ \\
6 & $1,2,3,4,5,6,7,8,9,13$ & $1,2,3,4,5,6,7,8,9,13$ & 13 \\
7 & $1,2,3,4,5,6,7,8,9,11,13$ & $1,2,3,4,5,6,7,8,9,11,13$ & $1,2,3,4,5,6,7,8,9,13$ \\
8 & $1,2,3,5,6,7,8,9,11$ & $1,2,3,5,6,7,8,9,11$ & $1,2,3,4,5,6,7,8,9,11,13$ \\
9 & $1,2,3,8,9,10,11,13$ & $1,2,3,8,9,10,11,13$ & $1,2,3,5,6,7,8,9,11$ & 3 \\
10 & $5,9,10,11$ & $5,9,10,11$ & $1,2,3,8,9,10,11,13$ \\
11 & $7,8,9,10,11,12$ & $7,8,9,10,11,12$ & $5,9,10,11$ \\
12 & $3,5,12,13$ & $3,5,12,13$ & $7,8,9,10,11,12$ & 7 \\
13 & $1,2,3,4,7,12,13$ & $1,2,3,4,7,12,13$ & $3,5,12,13$ & 6 \\
& & & $1,2,3,4,7,12,13$
\end{tabular}

Table 8. Transitivity check on the reachability matrix.

\begin{tabular}{|c|c|c|c|c|c|c|c|c|c|c|c|c|c|c|c|}
\hline IFCB Descriptions & (1) & (2) & (3) & (4) & (5) & (6) & (7) & (8) & (9) & (10) & (11) & (12) & (13) & Driving Power & Level \\
\hline 1 & 1 & 0 & $1 *$ & $1 *$ & $1 *$ & 1 & 1 & 1 & 0 & 0 & 1 & 0 & 1 & 9 & 2 \\
\hline 2 & 1 * & 1 & $1 *$ & 1 & 1 & $1 *$ & 1 & 0 & 0 & 0 & 1 & 0 & 1 & 9 & 2 \\
\hline 3 & 1 & 0 & 1 & 1 & 1 & $1^{*}$ & $1 *$ & $1 *$ & 1 & 0 & 1 & 0 & 0 & 9 & 2 \\
\hline 4 & 1 & 0 & $1 *$ & 1 & 1 & 1 & $1 *$ & 0 & 0 & 0 & 0 & 0 & 0 & 6 & 5 \\
\hline 5 & 1 * & $1^{*}$ & $1 *$ & $1 *$ & 1 & $1^{*}$ & $1 *$ & $1 *$ & 1 & 1 & 0 & 0 & 1 & 11 & 1 \\
\hline 6 & 1 & 1 & $1^{*}$ & 1 & $1^{*}$ & 1 & $1^{*}$ & 1 * & 0 & 0 & 0 & 0 & 0 & 8 & 3 \\
\hline 7 & 1 & 0 & 1 & 1 & $1^{*}$ & 1 & 1 & 0 & 0 & 0 & 0 & 0 & 1 & 7 & 4 \\
\hline 8 & 1 * & 0 & $1^{*}$ & 1 & $1^{*}$ & 1 & 0 & 1 & 0 & 0 & 0 & 0 & 0 & 6 & 5 \\
\hline 9 & 0 & 0 & $1^{*}$ & 0 & 0 & 0 & 0 & 0 & 1 & $1^{*}$ & 1 & 1 & 0 & 5 & 6 \\
\hline 10 & 0 & 0 & 1 & 1 & $1^{*}$ & 0 & 0 & 0 & $1^{*}$ & 1 & 1 & 1 & 0 & 7 & 4 \\
\hline 11 & 1 & 1 & 1 & 0 & 1 & 0 & 0 & 1 & 0 & 0 & 1 & 1 & 1 & 8 & 3 \\
\hline 12 & 0 & 0 & 1 & 0 & $1^{*}$ & 0 & 0 & 1 & 0 & 0 & 1 & 1 & 0 & 5 & 6 \\
\hline 13 & 0 & 0 & $1^{*}$ & 0 & 0 & 0 & 0 & 0 & 0 & 0 & 0 & 0 & 1 & 2 & 7 \\
\hline Dependence power & 9 & 4 & 13 & 9 & 11 & 7 & 7 & 7 & 5 & 3 & 7 & 4 & 6 & & \\
\hline
\end{tabular}




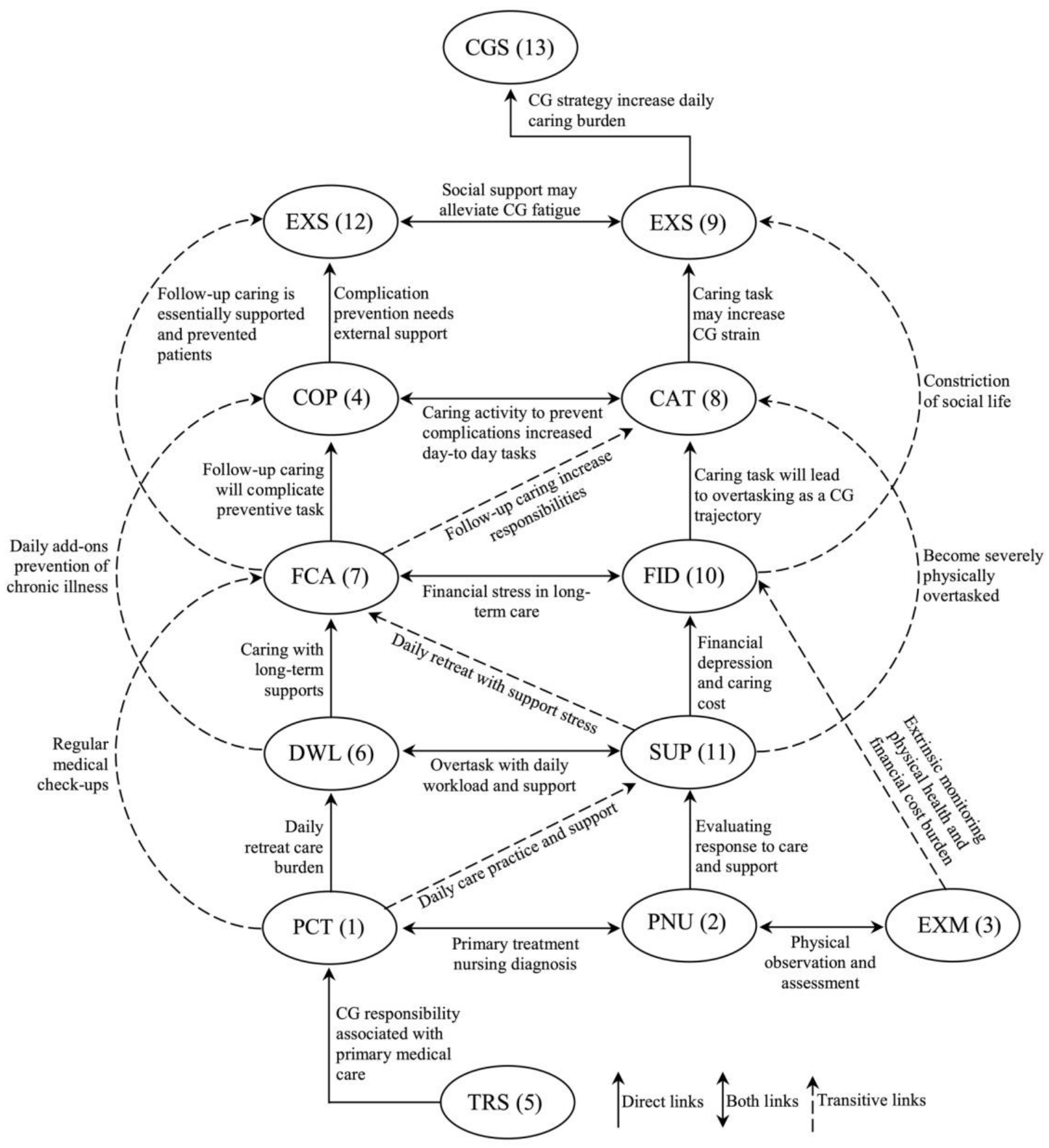

Figure 2. Structural model of the TISM.

\subsection{TISM of MICMAC Analysis}

The MICMAC analysis revealed thirteen factors enabled by the TISM approach to categorize the four clusters (autonomous, linkage, dependent and independent). The relationship of the interpretive matrix between palliative care and IFCB is illustrated in Table 9. The principles of the interpretive matrix and significant transitive links are presented in Figure 3. The driving and dependence diagram of the IFCB with CIBEPs is presented in Figure 4. 
Table 9. Interpretive matrix.

\begin{tabular}{|c|c|c|c|c|c|c|c|c|c|c|c|c|c|}
\hline IFCB & (1) & (2) & (3) & (4) & (5) & (6) & (7) & (8) & (9) & (10) & (11) & (12) & (13) \\
\hline 1 & 1 & & & & & & & & & & & & \\
\hline 2 & 0 & 1 & & & & & & & & & & & \\
\hline 3 & 0 & 1 & 1 & & & & & & & & & & \\
\hline 4 & 0 & 1 & 1 & 1 & & & & & & & & & \\
\hline 5 & 1 & 1 & 1 & 1 & 1 & & & & & & & & \\
\hline 6 & 1 & 1 & 1 & 1 & 1 & 1 & & & & & & & \\
\hline 7 & 0 & 1 & 0 & 0 & 1 & 1 & 1 & & & & & & \\
\hline 8 & 0 & 1 & 0 & 0 & 1 & 1 & 1 & 1 & & & & & \\
\hline 9 & 0 & 0 & 0 & 0 & 1 & 1 & 1 & 1 & 1 & & & & \\
\hline 10 & 1 & 1 & 1 & 0 & 1 & 0 & 1 & 0 & 0 & 1 & & & \\
\hline 11 & 1 & 1 & 1 & 1 & 1 & 1 & 1 & 1 & 0 & 0 & 1 & & \\
\hline 12 & 0 & 0 & 0 & 0 & 0 & 0 & 0 & 0 & 1 & 1 & 1 & 1 & \\
\hline 13 & 1 & 1 & 0 & 0 & 1 & 0 & 1 & 0 & 0 & 0 & 0 & 0 & 1 \\
\hline
\end{tabular}

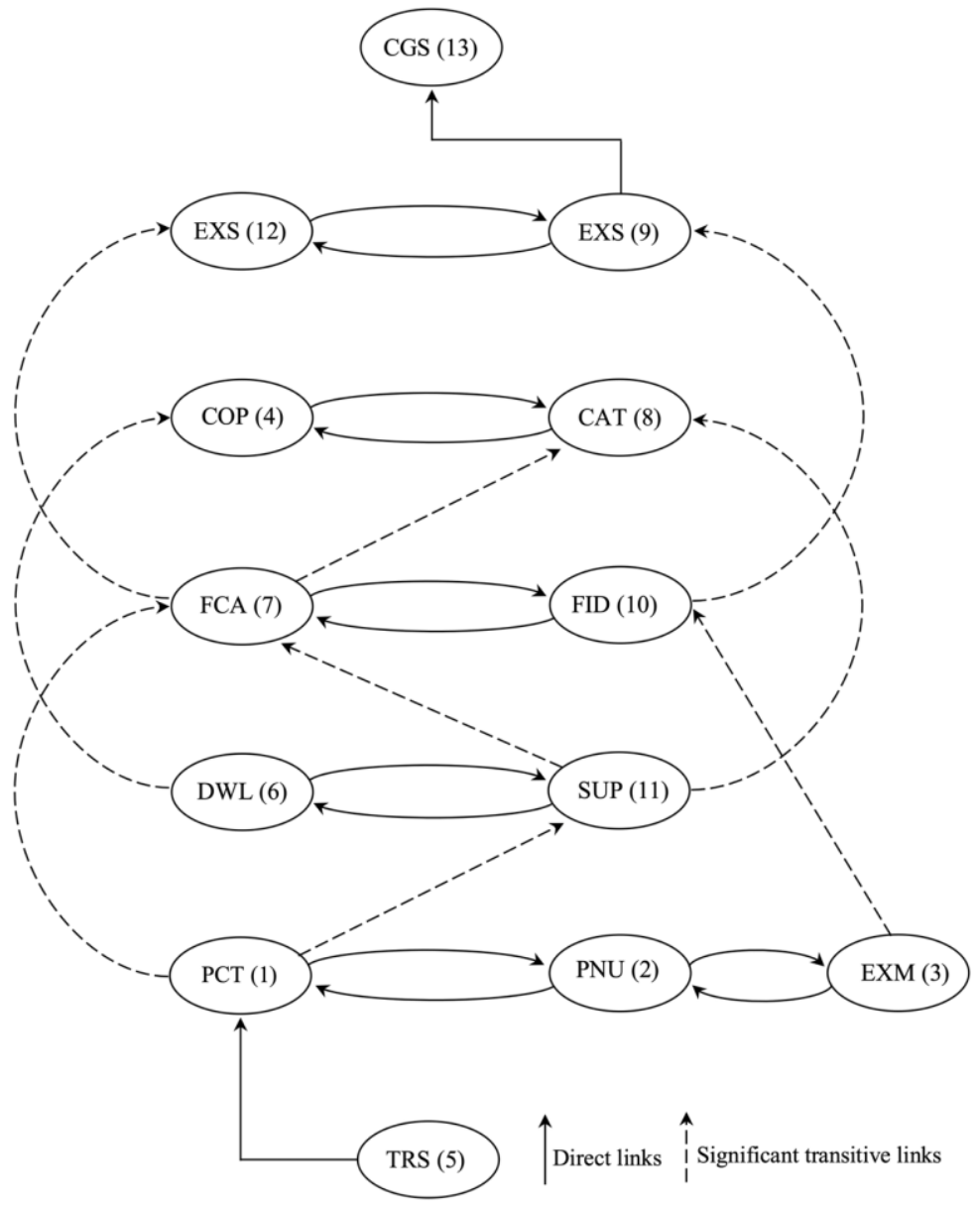

Figure 3. Direct with significant transitive links.

Cluster I-Autonomous factors. The MICMAC indicated that the autonomous factor for the driving power on the dependence power, thus, was positioned in cluster one, which is usually the strong driving and dependence power. As such, CGS has a weak driving power of 2 and a strong dependence power of 6 , respectively.

Cluster II-Dependent factors. The dependent factors had strong driving power and weak dependence power on the IFCB of caring for CIBEPs. The critical factors of CVS and EXS had driving powers of 5 and 5, and dependence powers of 5 and 4, respectively. The TISM showed that the factor in the dependent clusters depended on the other factors, which do not support influential power. 
Cluster III-Linkage factors. The MICMAC showed strong driving power and dependence power on the IFCB of caring for CIBEPs. The enabling tasks of PCT, PNU, EXM and TRS had driving powers of 9,9,9 and 11, and dependence powers of 9, 4, 13 and 11, respectively. The critical factors were otherwise linked because of the influential power of other factors and vice versa, which had strong driving and dependence power. Since these linking factors affect the IFCB of caring for CIBEPs, they may increase primary care treatment associated with taking responsibilities.

Cluster IV-Independent factor. The TISM illustrated that independent factors had weak driving but strong dependence power. The FID and SUP showed weak driving powers of 4 and 3, and dependence powers of 3 and 8, respectively. The critical factors of the ICB are presumed to play an important role in caring for CIBEPs, influencing all critical factors to achieve palliative care.

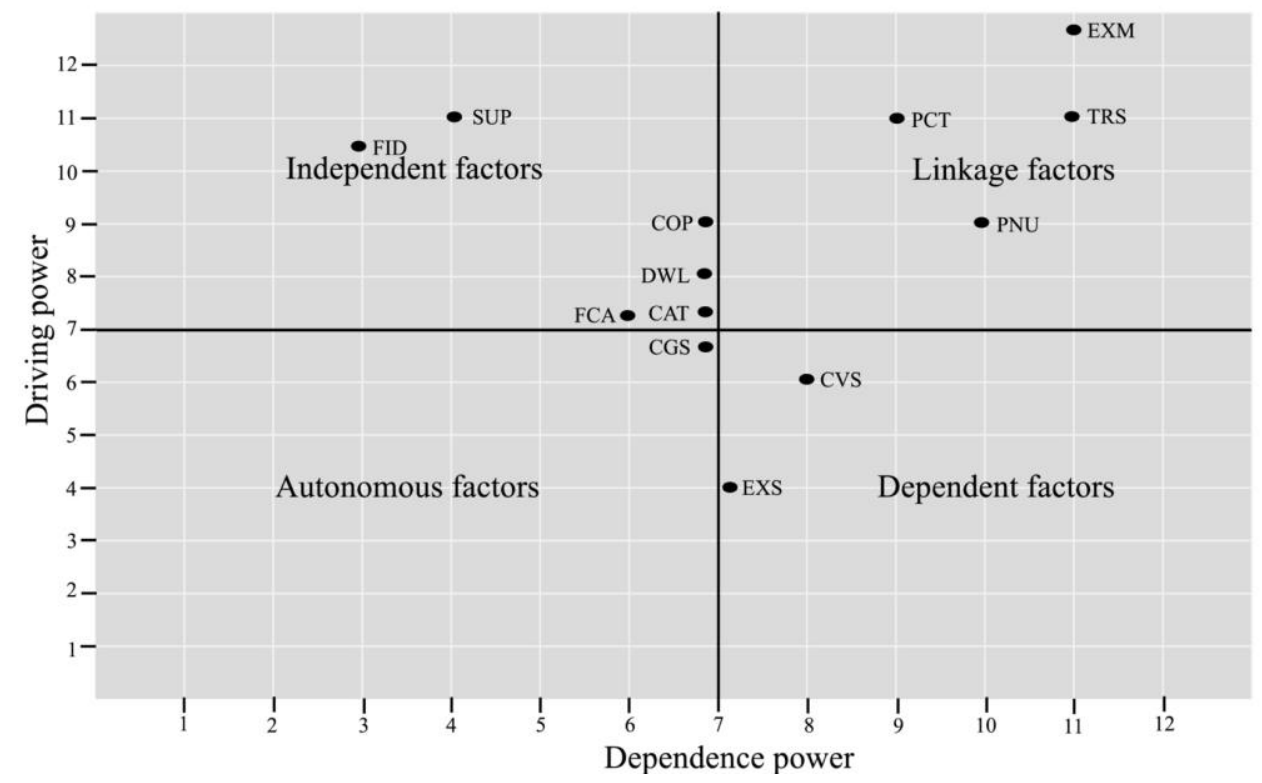

Figure 4. Driving power and dependence power matrix.

\section{Discussion}

\subsection{Theory Implications}

The present study provides new insights regarding the IFCB of caring for CIBEPS in Thailand, bridging the gap in the literature regarding family caregivers [8], caregiver research [62] and theory into practice [63]. This is an important theoretical contribution as it fills the gap of palliative care theory [63-65]. Most IFCB studies have focused on stress theory [66], caregiver identity theory [67] and single approaches to the care burden [16]. Recent articles focused on IFCB theories [43], grounded theory approach to IFCB [68] and gender role in caregiving [69]. There is a lack of data linking specific contexts, patient characteristics and the caregivers' burden.

This study attempted to fill the gap of caregiver theory regarding IFCB in palliative care. We found that the factors contributing to IFCB were the daily workload associated with carrying out responsibilities for CIBEPs. This finding is consistent with Zubaidi et al. [40], who showed that IFCB in palliative care overload is associated with malignancy, long hours of caregiving, and symptoms. Indeed, the IFCB is associated with caregiving strain, followup caring and financial distress. Our article concurs with the results of Leung et al. [49], showing that IFCB in palliative care is associated with caregiver fatigue, daily activities and primary caring.

The IFCB involves various caring tasks, supporting the patient and performing nursing tasks in line with Bekdemir and Ilhan [70], who found that the informal family caring of CIBEPs comprised health constraints, activities of daily living and physical burden. Some studies identified that caregivers and patients in palliative care [29] associated with the 
psychological burden of caring for CIBEPs [24]. The findings also suggest that the caregiver burden based on primary care treatment, extrinsic monitoring, complication prevention and the caregiving strategy is crucially important $[2,6]$ - the IFCB is not just a trait $[5,38,40,43]$, which is taking responsibilities $[69,71]$.

The IFCB of caring for CIBEPs is a multidimensional model of physical, social and financial burden $[4,13,15]$, while some studies have suggested the use of online photovoice (OPV), which could help to reduce the care burden [72,73]. Creative methods of exploring the use of OPV with caregivers help to engage them in ways that are meaningful and investigative $[74,75]$. This validated approach uses strengthened theoretical contributions and enriched empirical data support. The OPV effectively engaged respondents who would then go on to meet and discuss their experiences of caregivers caring for CIBEPs.

\subsection{Practice Implications}

This study has various practical implications. First, the IFCB of caring for CIBEPs is undeniable, and thus caregivers need to be supported by complication prevention (early detection, daily add-on prevention, follow-up caring day-to-day tasks and external support) to help reduce their daily workload, caring tasks and follow-up care. The caregivers providing palliative care also need a caring strategy to help decrease the strain and care burden. Finally, ideally, long-term mental health, education, research, service and administration would be implemented to reduce the care burden associated with caring for CIBEPs. It is important to note that caregiver burden in future caring may be linked to healthcare, in planning for the caring future and caregivers' aspects of caregiving.

\subsection{Limitations and Further Research Directions}

The present article has some limitations. First, the most obvious limitation of this article is its design as a single method of a total interpretive structural modeling approach. Second, this article is limited by the small sample size, and so may not accurately represent all groups of informal caregivers in Thailand. In-depth interviews were conducted using a fixed format questionnaire, which may have introduced bias in the data collection. Third, the findings were based on the respondents' views, and thus cannot be generalized to other contexts. Future work should consider mixed methods, which are important to gauge the IFCB of caring for CIBEPs. Future studies should investigate different groups and clusters of IFCB, have a larger sample size, and should validate and generalize the results with empirical models.

Author Contributions: Conceptualization, J.M. and H.D.; methodology, J.M. and H.D.; formal analysis, J.M. and H.D.; investigation, J.M. and H.D.; writing-original draft preparation, J.M. and H.D.; writing-review and editing, J.M. and H.D. All authors have read and agreed to the published version of the manuscript.

Funding: This research was funded by the Thammasat University Research Fund (Grant Number. TUFT 92/2564) and the National Research Council of Thailand (NRCT).

Institutional Review Board Statement: This study was approved by the IRB at the Thammasat University and was conducted according to the Declaration of Helsinki, the Belmon Report, CIOMS Guidelines and International Practice (ICH-GCP) (COA No. 117/2562, Ref No. 065/2562). All respondents were fully informed of the study objectives, content, procedures and principles of confidentiality.

Informed Consent Statement: Informed consent was obtained from all subjects involved in the study.

Data Availability Statement: Data will be available upon reasonable request to the corresponding author.

Conflicts of Interest: The authors declare no conflict of interest. 


\section{References}

1. Tangchonlatip, K.; Chamratrithirong, A.; Lucktong, A. The potential for civic engagement of older persons in the aging society of Thailand. J. Health Res. 2019, 33, 386-397. [CrossRef]

2. Mamom, J.; Ruchiwit, M.; Hain, D. Strategies of repositioning for effective pressure ulcer prevention in immobilized patients in home-based palliative care: An integrative literature reviews. J. Med. Assoc. Thai. 2020, 103, 111-117.

3. Kulkantrakorn, K.; Suksasunee, D. Clinical, electrodiagnostic, and outcome correlation in ALS patients in Thailand. J. Clin. Neurosci. 2017, 43, 165-169. [CrossRef]

4. Suriyanrattakorn, S.; Chang, C.L. Long-term care (LTC) policy in Thailand on the homebound and bedridden elderly happiness. Health Policy Open 2021, 2, 100026. [CrossRef]

5. Choi, S.; Seo, J. Analysis of caregiver burden in palliative care: An integrated review. Nurs. For. 2019, 54, 280-290. [CrossRef] [PubMed]

6. Hsiao, C.Y.; Lu, H.L.; Tsai, Y.F. Caregiver burden and health-related quality of life among primary family caregivers of individuals with schizophrenia: A cross-sectional study. Qual. Life. Res. 2020, 29, 2745-2757. [CrossRef] [PubMed]

7. Del-Pino-Casado, R.; Cardosa, M.R.; López-Martínez, C.; Orgeta, V. The association between subjective caregiver burden and depressive symptoms in carers of older relatives: A systematic review and meta-analysis. PLoS ONE 2019, 14, e0217648. [CrossRef] [PubMed]

8. Tramonti, F.; Bonfiglio, L.; Bongioanni, P.; Belviso, C.; Fanciullacci, C.; Rossi, B.; Chisari, C.; Carboncini, M.C. Caregiver burden and family functioning in different neurological diseases. Psychol. Health Med. 2019, 24, 27-34. [CrossRef]

9. Bialon, L.N.; Coke, S. A study on caregiver burden: Stressors, challenges, and possible solutions. Am. J. Hosp. Palliat. Care 2012, 29, 210-218. [CrossRef]

10. Yotani, N.; Ishiguro, A.; Sakai, H.; Ohfuji, S.; Fukushima, W.; Hirota, Y. Factor-Associated caregiver burden in medically complex patients with special health-care needs. Pediatr. Int. 2014, 56, 742-747. [CrossRef]

11. Hartmann, M.L.; Mello, J.D.A.; Anthierens, S.; Declercq, A.; Durme, T.V.; Cès, S.R. Caring for a frail older person: The association between informal caregiver burden and being unsatisfied with support from family and friends. Age Aging 2019, 48, 658-664. [CrossRef] [PubMed]

12. Pristavec, T.; Luth, E.A. Informal caregiver burden, benefits, and older adult Mortality: A survival analysis. J. Gerontol. B Psychol. Sci. Soc. Sci. 2020, 75, 2193-2206. [CrossRef] [PubMed]

13. Chong, P.H.; Molina, J.A.D.C.; Teo, K.; Tan, W.S. Paediatric palliative care improves patient outcomes and reduces healthcare costs: Evaluation of a home-based program. BMC Palliat. Care 2018, 17, 11. [CrossRef]

14. Pereira-Morales, A.; Valencia, L.; Rojas, L. Impact of the caregiver burden on the effectiveness of a home-based palliative care program: A mediation analysis. Palliat. Support Care 2020, 18, 332-338. [CrossRef] [PubMed]

15. Palacio, C.; Krikorian, A.; Limonero, J. The influence of psychological factors on the burden of caregivers of patients with advanced cancer: Resiliency and caregiver burden. Palliat. Support Care 2018, 16, 269-277. [CrossRef] [PubMed]

16. Lu, N.; Liu, J.; Lou, V.W.O. Caring for frail elders with musculoskeletal conditions and family caregivers' subjective well-being: The role of multidimensional caregiver burden. Arch. Gerontol. Geriatr. 2015, 61, 411-418. [CrossRef]

17. Bauer, J.; Sousa-Poza, A. Impacts of informal caregiving on caregiver employment, health, and family. Popul. Age 2015, 8, 113-145. [CrossRef]

18. Unite Nation. World Population Prospect 2019; Department of Economic and Social Affairs, Population Division: New York, NY, USA, 2019; Available online: https://population.un.org/wpp/Publications/Files/WPP2019_Highlights.pdf (accessed on 21 December 2021).

19. Chiaranai, C.; Chularee, S.; Srithongluang, S. Older people living with chronic illness. Geriatr. Nurs. 2018, 39, 513-520. [CrossRef]

20. Tantirat, P.; Suphanchaimat, R.; Rattanathumsakul, T.; Noree, T. Projection of the number of elderly in different health states in Thailand in the next ten years, 2020-2030. Int. J. Environ. Res. Public Health 2020, 17, 8703. [CrossRef]

21. Kaufman, N.D.; Chasombat, S.; Tanomsingh, S.; Rajataramya, B.; Potempa, K. Public health in Thailand: Emerging focus on non-communicable diseases. Int. J. Health Plann. Manag. 2011, 26, 197-212. [CrossRef]

22. Chamroonsawasdi, K.; Chottanapund, S.; Tunyasitthisundhorn, P.; Phokaewsuksa, N.; Ruksujarit, T.; Phasuksathaporn, P. Development and validation of a questionnaire to assess knowledge, threat and coping appraisal, and intention to practice healthy behaviors related to non-communicable diseases in the Thai population. Behav. Sci. 2017, 7, 20. [CrossRef]

23. Nawamawat, J.; Prasittichok, W.; Prompradit, T.; Chatchawanteerapong, S.; Sittisart, V. Prevalence, and characteristics of risk factors for non-communicable diseases in semi-urban communities: Nakhonsawan, Thailand. J. Health Res. 2020, 34, 295-303. [CrossRef]

24. Oechsle, K.; Ullrich, A.; Marx, G.; Benze, G.; Heine, J.; Dickel, L.M.; Zhang, Y.; Wowretzko, F.; Wendt, K.N.; Nauck, F.; et al. Psychological burden in family caregivers of patients with advanced cancer at initiation of specialist inpatient palliative care. BMC Palliat. Care 2019, 18, 102. [CrossRef] [PubMed]

25. Dionne-Odom, J.N.; Ornstein, K.A.; Kent, E.E. What do family caregivers know about palliative care? Results from a national survey. Palliat. Support Care 2019, 17, 643-649. [CrossRef] [PubMed]

26. Tarberg, A.S.; Kvangarsnes, M.; Hole, T.; Thronæs, M.; Madssen, T.S.; Landstad, B.J. Silent voices: Family caregivers' narratives of involvement in palliative care. Nurs. Open 2019, 6, 1446-1454. [CrossRef] [PubMed] 
27. Williams-Reade, J.; Lamson, A.L.; Knight, S.M.; White, M.B.; Ballard, S.M.; Desai, P.P. Paediatric palliative care: A review of needs, obstacles, and the future. J. Nurs. Manag. 2015, 23, 4-14. [CrossRef]

28. El-Jawahri, A.; Greer, J.A.; Pirl, W.F.; Park, E.R.; Jackson, V.A.; Back, A.L.; Kamdar, M.; Jacobsen, J.; Chittenden, E.H.; Rinaldi, S.P.; et al. Effects of early integrated palliative care on caregivers of patients with lung and gastrointestinal cancer: A randomized clinical trial. Oncologist 2017, 22, 1528-1534. [CrossRef]

29. Aoun, S.M.; Rumbold, B.; Howting, D.; Bolleter, A.; Breen, L.J. Bereavement support for family caregivers: The gap between guidelines and practice in palliative care. PLOS ONE 2017, 12, e0184750. [CrossRef]

30. Brogaard, T.; Jensen, A.B.; Sokolowski, I.; Olesen, F.; Neergaard, M.A. Who is the key worker in palliative home care? Scand. J. Prim. Health Care 2011, 29, 150-156. [CrossRef]

31. Ho, A.H.Y.; Car, J.; Ho, M.R.; Tan-Ho, G.; Choo, P.Y.; Patinadan, P.V.; Chong, P.H.; Ong, W.Y.; Fan, G.; Tan, Y.P.; et al. A novel Family Dignity Intervention (FDI) for enhancing and informing holistic palliative care in Asia: Study protocol for a randomized controlled trial. Trials 2017, 18, 587. [CrossRef]

32. Singh, T.; Harding, R. Palliative care in South Asia: A systematic review of the evidence for care models, interventions, and outcomes. BMC Res. Notes 2015, 8, 172. [CrossRef]

33. Radbruch, L.; Lima, L.D.; Knaul, F.; Wenk, R.; Ali, Z.; Bhatnaghar, S.; Blanchard, C.; Bruera, E.; Buitrago, R.; Burla, C.; et al Redefining palliative care: A new consensus-based definition. J. Pain Symptom Manag. 2020, 60, 754-764. [CrossRef]

34. Hoerger, M.; Greer, J.A.; Jackson, V.A.; Park, E.R.; Pirl, W.F.; El-Jawahri, A.; Gallagher, E.R.; Hagan, T.; Jacobsen, J.; Perry, L.M.; et al. Defining the elements of early palliative care that are associated with patient-reported outcomes and the delivery of end-of-life care. J. Clin. Oncol. 2018, 36, 1096-1102. [CrossRef]

35. Danielsen, B.V.; Sand, A.M.; Rosland, J.H.; Førland, O. Experiences, and challenges of home care nurses and general practitioners in home-based palliative care-A qualitative study. BMC Palliat Care. 2018, 17, 95. [CrossRef]

36. Morey, T.; Scott, M.; Saunders, S.; Varenbut, J.; Howard, M.; Tanuseputro, P.; Webber, C.; Killackey, T.; Wentlandt, K.; Zimmermann, C.; et al. Transitioning from hospital to palliative care at home: Patient and caregiver perceptions of continuity of care. J. Pain Symptom Manag. 2021, 62, 233-241. [CrossRef]

37. Duc, J.K.; Herbert, A.R.; Heussler, H.S. Paediatric palliative care and intellectual disability-A unique context. J. Appl. Res. Intellect. Disabil. 2017, 30, 1111-1124. [CrossRef]

38. Ng, A.Y.M.; Wong, F.K.Y. Effects of a home-based palliative heart failure program on quality of life, symptom burden, satisfaction, and caregiver burden: A randomized controlled trial. J. Pain Sympt. Manag. 2018, 55, 1-11. [CrossRef] [PubMed]

39. Wang, T.; Molassiotis, A.; Tan, J.Y.; Chung, B.P.M.; Huang, H.Q. Prevalence and correlates of unmet palliative care needs in dyads of Chinese patients with advanced cancer and their informal caregivers: A cross-sectional survey. Support Care Cancer 2021, 29, 1683-1698. [CrossRef] [PubMed]

40. Zubaidi, Z.S.A.; Ariffin, F.; Oun, C.T.C.; Katiman, D. Caregiver burden among informal caregivers in the largest specialized palliative care unit in Malaysia: A cross-sectional study. BMC Palliat. Care 2020, 19, 186.

41. Allen, A.P.; Buckley, M.M.; Cryan, J.F.; Chorcoráin, A.N.; Dinan, T.G.; Kearney, P.M.; O'Caoimh, R.; Calnan, M.; Clarke, G.; Molloy, D.W. Informal caregiving for dementia patients: The contribution of patient characteristics and behaviors to caregiver burden Age Ageing 2019, 49, 52-56. [CrossRef]

42. Abreu, W.; Tolson, D.; Jackson, G.A.; Costa, N. A cross-sectional study of family caregiver burden and psychological distress linked to frailty and functional dependency of a relative with advanced dementia. Dementia 2020, 19, 301-318. [CrossRef]

43. Kayaalp, A.; Page, K.J.; Rospenda, K.M. Caregiver burden, work-family conflict, family-work conflict, and mental health of caregivers: A mediational longitudinal study. Work Stress 2021, 35, 217-240. [CrossRef]

44. McCabe, M.; You, E.; Tatangelo, G. Hearing their voice: A systematic review of dementia family caregivers' needs. Gerontologist 2016, 56, 70-88. [CrossRef]

45. Joyce, B.T.; Berman, R.; Lau, D.T. Formal and informal support of family caregivers managing medications for patients who receive end-of-life care at home: A cross-sectional survey of caregivers. Palliat. Med. 2014, 28, 1146-1155. [CrossRef] [PubMed]

46. Limpawattana, P.; Theeranut, A.; Chindaprasirt, J.; Sawanyawisuth, K.; Pimporm, J. Caregivers burden of older adults with chronic illnesses in the community: A cross-sectional study. J. Community Health 2013, 38, 40-45. [CrossRef]

47. Ajay, S.; Kasthuri, A.; Kiran, P.; Malhotra, R. Association of impairments of older persons with caregiver burden among family caregivers: Findings from rural South India. Arch. Gerontol. Geriatr. 2017, 68, 143-148. [CrossRef] [PubMed]

48. Lloyd, J.; Muers, J.; Patterson, T.G.; Marczak, M. Self-Compassion, coping strategies, and caregiver burden in caregivers of people with dementia. Clin. Gerontol. 2019, 42, 47-59. [CrossRef] [PubMed]

49. Leung, D.Y.P.; Chan, H.Y.L.; Chiu, P.K.C.; Lo, R.S.K.; Lee, L.L.Y. Source of social support and caregiving self-efficacy on caregiver burden and patient's quality of life: A path analysis on patients with palliative care needs and their caregivers. Int. J. Environ. Res. Public Health 2020, 17, 5457. [CrossRef]

50. Lethin, C.; Leino-Kilpi, H.; Bleijlevens, M.H.; Stephan, A.; Martin, M.S.; Nilsson, K.; Nilsson, C.; Zabalegui, A.; Karlsson, S. Predicting caregiver burden in informal caregivers caring for persons with dementia living at home-A follow-up cohort study. Dementia 2020, 19, 640-660. [CrossRef]

51. Tulek, Z.; Baykal, D.; Erturk, S.; Bilgic, B.; Hanagasi, H.; Gurvit, I.H. Caregiver burden, quality of life and related factors in family caregivers of dementia patients in Turkey. Issues Ment. Health Nurs. 2020, 41, 741-749. [CrossRef] 
52. Konerding, U.; Bowen, T.; Forte, P.; Karampli, E.; Malmström, T.; Pavi, E.; Torkki, P.; Graessel, E. Do caregiver characteristics affect caregiver burden differently in different countries? Am. J. Alzheimer's Dis. Other Demen. 2019, 34, 148-152. [CrossRef] [PubMed]

53. Warfield, J.N. Developing interconnection matrices in structural modeling. IEEE Trans. Syst. Man. Cyber 1974, 4, 81-87. [CrossRef]

54. Agarwal, A.; Shankar, R.; Tiwari, M.K. Modeling agility of supply chain. Indust. Mark. Manag. 2007, 36, 443-457. [CrossRef]

55. Watson, R.H. Interpretive structural modeling-A useful tool for technology assessment? Technol. Forec. Soc. Chan. 1978, 11, 165-185. [CrossRef]

56. Sharma, H.D.; Sushil, K.B.; Gupta, A.D. A structural approach to the analysis of causes of system waste in the Indian economy. Syst. Res. 1994, 11, 17-41. [CrossRef]

57. Mathiyazhagan, K.; Govindan, K.; NoorulHaq, A.; Geng, Y. An ISM approach for the barrier analysis in implementing green supply chain management. J. Clean. Produc. 2013, 47, 283-297. [CrossRef]

58. Attri, R.; Dev, N.; Sharma, V. Interpretive structural modeling (ISM) approach: An overview. Res. J. Manag. Sci. 2013, 2, 3-8.

59. Sushil. How to check the correctness of total interpretive structural models? Ann. Oper. Res. 2018, 270, 473-487. [CrossRef]

60. Sushil. Interpreting the interpretive structural model. Glob. J. Flex. Syst. Manag. 2012, 13, 87-106. [CrossRef]

61. Singh, M.D.; Kant, R. Knowledge management barriers: An interpretive structural modeling approach. Int. J. Manag. Sci. Eng. Manag. 2008, 3, 141-150. [CrossRef]

62. Hunt, C.K. Concepts in caregiver research. J. Nurs. Schol. 2003, 35, 27-32. [CrossRef]

63. Polacsek, M.; Boardman, G.; McCann, T.V. Paying patient and caregiver research participants: Putting theory into practice. J. Advan. Nurs. 2017, 73, 847-856. [CrossRef]

64. Hudson, P.; Trauer, T.; Kelly, B.; O'Connor, M.; Thomas, K.; Summers, M.; Zordan, R.; White, V. Reducing the psychological distress of family caregivers of home-based palliative care patients: Short-Term effects from a randomized controlled trial. Psycho-Oncology 2013, 22, 1987-1993. [CrossRef]

65. Wu, M.P.; Huang, S.J.; Tsao, L.I. The life experiences among primary family caregivers of home-based palliative care. Am. J. Hosp. Palliat. Care 2020, 37, 816-822. [CrossRef] [PubMed]

66. Bastawrous, M. Caregiver burden-A critical discussion. Int. J. Nurs. Stud. 2013, 50, 431-441. [CrossRef] [PubMed]

67. Miller, V.J.; Killian, M.O.; Fields, N. Caregiver identity theory and predictors of burden and depression: Findings from the REACH II study. Aging Ment. Health 2020, 24, 212-220. [CrossRef] [PubMed]

68. Bassola, B.; Cilluffo, S.; Lusignani, M. Going inside the relationship between caregiver and care-receiver with amyotrophic lateral sclerosis in Italy, a grounded theory study. Health Soc. Care Comm. 2021, 29, 1083-1090. [CrossRef] [PubMed]

69. Halinski, M.; Duxbury, L.; Stevenson, M. Employed caregivers' response to family-role overload: The role of control-at-home and caregiver type. J. Bus. Psychol. 2020, 35, 99-115. [CrossRef]

70. Bekdemir, A.; Ilhan, N. Predictors of caregiver burden in caregivers of bedridden patients. J. Nurs. Res. 2019, 27, e24. [CrossRef]

71. Liu, Z.; Heffernan, C.; Tan, J. Caregiver burden: A concept analysis. Int. J. Nurs. Sci. 2020, 7, 438-445. [CrossRef]

72. Tanhan, A.; Strack, R.W. Online photovoice to explore and advocate for Muslim biopsychosocial spiritual wellbeing and issues: Ecological systems theory and ally development. Curr. Psychol. 2020, 39, 2010-2025. [CrossRef]

73. Tajuria, G.; Read, S.; Priest, H.M. Using photovoice as a method to engage bereaved adults with intellectual disabilities in research: Listening, learning and developing good practice principles. Adv. Ment. Health Intell. Disab. 2017, 11, 196-206. [CrossRef]

74. Tanhan, A.; Arslan, G.; Yavuz, K.F.; Young, J.S.; Çiçek, İ.; Akkurt, M.N.; Ulus, İ.Ç.; Görünmek, E.; Demir, R.; Kürker, F.; et al. A constructive understanding of mental health facilitators and barriers through Online Photovoice (OPV) during COVID-19. ESAM Ekon. Sos. Araştırmalar Dergisi. 2021, 2, 214-249.

75. Capous-Desyllas, M.; Perez, N.; Cisneros, T.; Missari, S. Unexpected caregiving in later Life: Illuminating the narratives of the resilience of grandmothers and relative caregivers through photovoice methodology. J. Gerontol. Soc. Work 2020, 63, 262-294. [CrossRef] [PubMed] 